\title{
Adult Romantic Attachment, Electronic Messaging, and Relationship Quality
}

\author{
Prit Y. Patel, Elizabeth A. Mahar, and Gregory D. Webster
}

Department of Psychology, University of Florida

Patel, P. Y., Mahar, E. A., \& Webster, G. D. (2022). Adult romantic attachment, electronic messaging, and relationship quality. Cyberpsychology, Behavior, and Social Networking. https://doi.org/10.1089/cyber.2021.0060 (Final publication: See Mary Ann Liebert, Inc.)

\section{Author Note}

\section{Corresponding Author}

Gregory D. Webster, Department of Psychology, University of Florida, P.O. Box 112250, Gainesville, FL 32611-2250 USA. Voice: +1-303-895-7312. Email: gdwebs@ufl.edu

\section{Acknowledgements}

This manuscript is based on the honors thesis of the first author (now at Miami University in Oxford, Ohio), which was supervised by the second author (now at the University of British Columbia in Vancouver, Canada), and indirectly supervised by the third author.

\section{Contribution Statement}

The first author designed and conducted the research, analyzed the data, and contributed to writing the manuscript. The second author contributed to conducting the research, analyzing the data, and writing and revising the manuscript. The third author contributed to analyzing the data and writing and revising the manuscript.

\section{Funding Statement}

This research was not funded.

\section{Author Disclosure Statement}

The authors have no known conflicts of interest to report or disclose. 


\begin{abstract}
The present study examined associations among adult romantic attachment, relationship quality, and electronic messaging frequency/preferences in 302 romantically-partnered undergraduates. Anxious people desired more frequent messages than they received, whereas avoidant people desired less frequent messages than they received. Anxious people received fewer messages from their partners, whereas avoidant people sent fewer messages to their partners. Additionally, anxious people took less time to respond to their partner than their partners took to respond to them, whereas avoidant people took more time to respond to their partner than their partners did to respond to them. Finally, the relation between message frequency satisfaction and relationship quality was stronger for more anxious people. These results suggest that individual differences in attachment dimensions related to differences in romantic messaging behavior in theoretically consistent ways.
\end{abstract}

Keywords: Romantic Relationships; Attachment; Anxious Attachment; Avoidant Attachment; Texting; Messaging 


\section{Adult Romantic Attachment, Electronic Messaging, and Relationship Quality}

Attachment affects a person's likelihood to seek support from a partner. For example, securely attached people tend to seek and provide support under distress, which may help maintain stronger interdependence and positive effects on their relationships. ${ }^{1}$ Avoidantly attached people are less likely to ask for help or reach out to support their partners, which can result in weaker interdependence and more negative relationship effects. ${ }^{1}$ Anxiously attached people often crave more emotional support from their romantic partners, view them as providing inconsistent support, which can lead to resentment and toxic relationships. ${ }^{1}$ Regarding social networking sites, anxious-preoccupied and avoidant adults are more likely to monitor their current or ex-partner's Facebook page.,3 More generally, attachment anxiety, but not avoidance, relates to problematic social media use. ${ }^{4}$

Whether and which attachment dimensions relate to how people engage with their romantic partners via messaging has produced mixed findings. One study found that avoidant attachment was related to less frequent text messaging, ${ }^{5}$ whereas another study found that text messaging was unrelated to either attachment dimension. ${ }^{6}$ People who reported a greater percentage of their partner interactions were conducted over text had higher avoidant and anxious attachment, suggesting that people who are more anxiously or avoidantly attached tend to rely more on texting. ${ }^{7}$ A recent study of young adult Americans in relationships found that smartphone use related to more affectionate communication between partners; however, smartphone dependency (addiction or excessive use) related to less affectionate communication and decreased relationship satisfaction. ${ }^{8}$

Because communication via electronic messaging is an important part of relationship maintenance, the present study examined how attachment dimensions relate to relationship 
quality and messaging characteristics (frequency, emotional content, messages sent vs. received, response latency, response interval). We aimed to expand on previous research by (a) examining the associations between attachment style and messaging frequency and (b) exploring how attachment relates to messages sent versus received, the amount of time it takes to respond to partners' messages, response intervals, and desired emotional content in messages. Whereas prior research only examined texting in romantic relationships, ${ }^{9}$ we examine all forms of computer- or smartphone-mediated communication. Based on the literature reviewed above and our own expectations, we developed six sets of specific hypotheses (Table 1).

\section{Method}

\section{Power and Participants}

We recruited introductory psychology students in romantic relationships from the University of Florida who participated in exchange for partial course credit. Using G*Power $3.1,{ }^{10}$ we determined a priori that $\geq 264$ cases were needed to achieve adequate power $(\geq .80$ at $\alpha=.05)$, assuming a small effect size $\left(f^{2}=.03\right)$. We determined this effect size based on prior studies ${ }^{11}$ and because of the additional power needed to detect interactions involving continuous variables. $^{12}$

Participants were 329 undergraduates. Of these, we excluded 23 who were not in a romantic relationship, three older participants $(>45)$ to increase sample homogeneity, and one because of a nonsensical response. The analyzed sample of 302 participants ranged in age from 18 to 32 years $(M=19.52, S D=1.67)$. Median relationship duration was 9.0 months $(M=14.95$, $S D=14.83$, range: $0.25-76$ ). Most student participants were heterosexual, White, and women (Table 2). Nine participants $(<3 \%)$ had sporadic missing data; we used pairwise deletion for each model. 


\section{Procedure}

Participants completed the online survey study using Qualtrics. The survey was approved by our university's human-subjects IRB and data collection occurred during 2019 and 2020. After giving informed consent, participants read a definition of messaging: "When we refer to 'messaging,' we are referring to any communication that occurs through the use of two or more electronic devices. Examples of messaging include SMS/texting, iMessage, WhatsApp, Facebook Messenger, and email." They then completed the measures below.

\section{Measures}

Participants reported demographic variables including gender, age, relationship duration, physical distance between themselves and their romantic partner, and the percentage of the interactions with their partner that were conducted through SMS/texting, face-to-face, phone calls, video calls, email, messaging applications. Participants also completed measures of romantic adult attachment, ${ }^{13,14}$ relationship quality, ${ }^{15}$ messaging frequency, messages sent to and received from partner, message response latency to and from partner, and typical and ideal message interval (see Table 3 for scale properties and item examples).

\section{Data Analysis}

We tested our hypotheses using regression models. All six behavioral variables (i.e., messages sent or received, message response latencies and intervals) produced positively skewed distributions and were log-transformed to produce normal distributions $\left(\ln (x+1) \cdot{ }^{16,17}\right.$ For models involving interactions, relevant predictor variables were mean-centered prior to calculating interaction terms, ${ }^{18}$ and all necessary interaction terms were included to avoid biasing the focal interactions. ${ }^{19}$ Data appear here: https://osf.io/rde7b 


\section{Results}

\section{Descriptive Statistics and Correlations}

Table 4 shows correlations and descriptive statistics for the variables used in subsequent regressions. People who had been together with their partner for longer tended to be more securely attached as higher levels of anxious attachment and avoidant attachment were each negatively associated with relationship duration. Controlling for gender and relationship duration had no systematic effects on the results below.

\section{Messaging Frequency Satisfaction and Attachment (H1)}

We regressed MFS onto both attachment dimensions, finding that anxious attachment was negatively related to MFS $\left(b=-0.49, t(299)=-6.86, p<.001, r_{\mathrm{p}}=-.37[-.46,-.27]\right)$, whereas avoidant attachment was unrelated to MFS $\left(b=-0.08, t(299)=-1.07, p=.285, r_{\mathrm{p}}=-.06[-.17, .05]\right)$.

\section{Attachment and Desired Messaging Frequency (H2a \& H2b)}

Regressing ideal message frequency on both attachment dimensions showed that anxious attachment related to wanting more frequent messages $\left(b=0.32, t(298)=6.18, p<.001, r_{\mathrm{p}}=.34\right.$ $[.23, .43])$, whereas avoidant attachment related to wanting less frequent messages $(b=-0.17$, $\left.t(298)=-3.21, p=.001, r_{\mathrm{p}}=-.18[-.29,-.07]\right)$.

\section{Attachment and Messages Sent versus Received (H3a \& H3b)}

We examined log messages sent to partners and received from partners during the past 24 hrs as a function of both attachment dimensions. People with higher avoidant attachment sent significantly fewer messages (Table 5, top), whereas people with higher anxious attachment received significantly fewer messages (Table 5, middle). Because log messages sent and received were highly correlated (.96), we summed raw messages sent and received, log-transformed these sums $(M=4.27, S D=1.16)$, and regressed them onto both attachment dimensions, finding that 
people with higher anxious attachment sent/received significantly fewer total messages, whereas people with higher avoidant attachment did not (Table 5, bottom).

\section{Attachment and Message Response Latency (H4a \& H4b)}

We examined the participants' reported message response latencies (log $\mathrm{min}$ ) for both themselves and their partners as a function of both attachment dimensions. People with higher avoidant attachment reported taking significantly longer to write back to their partner (Table 6 , top), whereas people with higher anxious attachment reported taking significantly longer to hear back from their partner (Table 6, middle). To examine differences between message response latencies, we regressed people's reported self latencies onto reports of their partner's latencies, finding that people with higher anxious attachment took significantly less time to write their partner than their partners did to write them, whereas people with higher avoidant attachment took significantly more time to write their partner than their partners did to write them (Table 6, bottom).

\section{Attachment and Message Response Intervals (H5a \& H5b)}

We examined the participants' reported message response intervals from their partners (log $\min )$ and their ideal response intervals from their partners (log min) — each as functions of both attachment dimensions. People with higher anxious attachment reported significantly longer message response intervals from their partners (Table 7, top), whereas people with higher avoidant attachment wanted significantly longer message response intervals from their partners (Table 7, middle). To examine differences between actual and ideal message response intervals from partners, we regressed actual intervals onto ideal intervals, finding that people with higher anxious attachment reported significantly longer message response intervals from their partners than what they wanted, whereas people with higher avoidant attachment reported significantly 
shorter message response intervals from their partners than what they wanted (Table 7, bottom).

\section{Attachment, Messaging Frequency Satisfaction, and Relationship Quality (H6a \& H6b)}

To test whether either anxious or avoidant attachment moderated the association between message frequency satisfaction (MFS) and relationship quality, we regressed relationship quality onto anxious attachment, avoidant attachment, MFS, and their three 2-way interactions (Table 8). Results showed that anxious attachment moderated the MFS effect in the expected direction (H6a; Figure 1), but avoidant attachment did not (H6b). For people scoring $1 S D$ below the anxious attachment mean, the simple slope between MFS and relationship quality was nonsignificant $\left(b=-0.068, t(295)=1.49, p=.138, r_{\mathrm{p}}=.09[-.03, .20]\right)$; for people scoring $1 S D$ above the anxious attachment mean, the simple slope between MFS and relationship quality was significantly positive $\left(b=0.169, t(295)=6.14, p<.001, r_{\mathrm{p}}=.34[.23, .43]\right)$.

\section{Discussion}

Our findings are unique in showing that the actual numbers of messages that people send to and receive from their romantic partners — and the latencies between them — correlate with anxious and avoidant attachment in theoretically consistent and meaningful ways. These findings are important because people's attachment dimensions may influence expectations about their own and their dating partner's electronic communication frequency. Thus, attachment mismatches (e.g., combining anxious and avoidant partners) may suffer from poor electronic communication expectations, and hence, relationship dissatisfaction.

Our findings were more consistent with prior research showing that avoidant attachment related to less frequent text messaging ${ }^{5}$ than other research showing no association. ${ }^{6}$ Because people who are more anxiously or avoidantly attached tend to rely more on texting (vs. other forms of communication) to interact with their partners, ${ }^{7}$ our findings suggest that understanding 
how attachment differences relate to communication are especially important as electronic romantic interactions become increasingly frequent. Our findings also advance adult attachment theory in at least two ways. First, they show that individual differences in both attachment dimensions have specific behavioral signatures regarding electronic communication-or lack thereof - among romantic partners. Second, they indirectly bolster theoretical accounts linking attachment to relationship satisfaction via effective communication.

\section{Limitations and Constraints on Generality}

Because recall memory is subject to cognitive biases and heuristics, ${ }^{20}$ there is doubtlessly some non-systematic measurement error in participants' estimates of message response latencies and intervals. Further, the generalizability of our findings is limited to our convenience sample of students enrolled in introductory psychology courses at the University of Florida, who were mostly White heterosexual women. ${ }^{21}$ Thus, these findings may not generalize to other, more diverse populations or cultures. For example, greater attachment avoidance is more strongly linked to heightened conflict, less perceived support, less investment, and poorer relationship satisfaction in societies that are more collectivist than the U.S. ${ }^{22}$ Moreover, because emojis can facilitate interpersonal connections by directly conveying emotional romantic content, future studies could explore how attachment is related to emoji use in romantic relationships. ${ }^{23}$

\section{Conclusions}

We hope that this study will enable a better understanding of how attachment relates to messaging frequency and how they interact in relation to relationship satisfaction. This study is important because it provides insight into how messaging and attachment dimensions relate to estimates of actual messaging behavior, including response latencies and intervals. The present results not only highlight the importance of messaging in romantic relationships, but also show 
how individual differences in anxious and avoidant attachment relate to people's expectations about messaging and even actual messaging frequency. We urge future researchers to focus on metrics including messages exchanged and response latencies because people's perceptions of their partner's messaging frequency — and how long it takes their partner to respond — are crucial to relationship communication and satisfaction. 


\section{References}

1. Simpson JA, Rholes WS, Nelligan JS. Support seeking and support giving within couples in an anxiety-provoking situation: The role of attachment styles. Journal of Personality and Social Psychology 1992; 62:434-446.

2. Fox J, Tokunaga RS. Romantic partner monitoring after breakups: Attachment, dependence, distress, and post-dissolution online surveillance via social networking sites. Cyberpsychology, Behavior, and Social Networking 2015; 18:491-498.

3. Fox J, Warber KM. Social networking sites in romantic relationship attachment, uncertainty, and partner surveillance on Facebook. Cyberpsychology, Behavior, and Social Networking $2014 ; 17: 3-7$.

4. Worsley JD, Mansfield R, Corcoran R. Attachment anxiety and problematic social media use: The mediating role of well-being. Cyberpsychology, Behavior, and Social Networking, $2018 ; 21: 563-568$.

5. Morey JN, Gentzler AL, Creasy B, Oberhauser AM, Westerman D. Young adults' use of communication technology within their romantic relationships and associations with attachment style. Computers in Human Behavior 2013; 29:1771-1778.

6. Jin B, Peña JF. Mobile communication in romantic relationships: Mobile phone use, relational uncertainty, love, commitment, and attachment styles. Communication Reports $2010 ; 23: 39-51$.

7. Luo, S. Effects of texting on satisfaction in romantic relationships: The role of attachment. Computers in Human Behavior 2014; 33:145-152. 
8. Lapierre MA, Custer BE. Testing relationships between smartphone engagement, romantic partner communication, and relationship satisfaction. Mobile Media \& Communication 2020. https://doi.org/10.1177/2050157920935163

9. Piwek L, Joinson A. "What do they snapchat about?" Patterns of use in time-limited instant messaging service. Computers in Human Behavior 2016; 54:358-367.

10. Faul F, Erdfelder E, Lang AG, Buchner A. G*Power 3: A flexible statistical power analysis program for the social, behavioral, and biomedical sciences. Behavior Research Methods 2007; 39:175-191.

11. Li T., Chan DK-S. How anxious and avoidant attachment affect romantic relationship quality differently: A meta-analytic review. European Journal of Social Psychology, 2012; 42:406419.

12. McClelland GH, Judd CM. Statistical difficulties of detecting interactions and moderator effects. Psychological Bulletin 1993; 114: 376-390.

13. Fraley RC, Waller NG, Brennan KA. An item-response theory analysis of self-report measures of adult attachment. Journal of Personality and Social Psychology 2000; 78: 350365.

14. Sibley CG, Liu JH. Short-term temporal stability and factor structure of the revised experiences in close relationships (ECR-R) measure of adult attachment. Personality and Individual Differences 2004; 36: 969-975.

15. Hendrick SS. A generic measure of relationship satisfaction. Journal of Marriage and Family 1988; 50:93-98. 
16. Hadden BW, Smith CV, Webster GD. Relationship duration moderates associations between attachment and relationship quality: Meta-analytic support for the temporal adult romantic attachment model. Personality and Social Psychology Review 2014; 18:42-58.

17. McClelland GH. Nasty data: Unruly, ill-mannered observations can ruin your analysis. In Reis HT, Judd CM, eds. Handbook of Research Methods in Social and Personality Psychology (2nd ed.). New York, NY: Cambridge University Press; 2014, pp. 608-626.

18. Aiken LS, West, SG. Multiple regression: Testing and interpreting interactions. Thousand Oaks, CA: SAGE Publications; 1991.

19. Yzerbyt VY, Muller D, Judd CM. Adjusting researchers' approach to adjustment: On the use of covariates when testing interactions. Journal of Experimental Social Psychology 2004; 40:424-431.

20. Gilovich T, Griffin D, Kahneman, D. (Eds.). Heuristics and Biases: The Psychology of Intuitive Judgment. 2002; Cambridge University Press.

21. Henrich J, Heine SJ, Norenzayan A. The weirdest people in the world? Behavioral and Brain Sciences 2010; 33:61-83.

22. Friedman M, Rholes WS, Simpson J, Bond M, Diaz-Loving R, Chan C. Attachment avoidance and the cultural fit hypothesis: A cross-cultural investigation. Personal Relationships 2010; 17:107-126.

23. Gesselman AN, Ta VP, Garcia JR. Worth a thousand interpersonal words: Emoji as affective signals for relationship-oriented digital communication. PLoS ONE 2019; 14:e0221297. 
Table 1. Hypotheses

\begin{tabular}{llc}
\hline No. & \multicolumn{1}{c}{ Description } & Support \\
\hline 1. & $\begin{array}{l}\text { Both anxious (H1a) and avoidant (H1b) attachment will negatively relate to } \\
\text { message frequency satisfaction. }\end{array}$ & Yes/No \\
& & People scoring higher on anxious attachment will desire more frequent
\end{tabular}
messages than they receive $(\mathrm{H} 2 \mathrm{a})$, whereas people higher in avoidant attachment will desire less frequent messages than they receive (H2b).

3. We initially hypothesized that people higher in anxious attachment would Yes/Yes report sending more messages to their partner than they received, whereas people higher in avoidant attachment would report sending fewer messages than they received; however, because of the high correlation (.96) between messages sent and received, a reviewer advised running separate analyses for each. Thus, we hypothesized that people higher in anxious attachment would report receiving fewer messages (H3a), whereas people higher in avoidant attachment would report sending fewer messages (H3b). As an exploratory exercise, we also examined total messages sent and received as an outcome.

4. People higher in anxious attachment will reply faster to their partner's messages (shorter response latencies) than their partner replies to them (H4a), whereas people higher in avoidant attachment will reply slower to their partner's messages (longer response latencies) than their partner replies to them (H4b). On an exploratory basis, we also examine one's own and one's partner's response latencies as separate outcomes.

5. People higher in anxious attachment will report that the time in between their Yes/Yes partner's messages (actual response interval) will be longer than what they desire (ideal response interval; H5a), whereas people higher in avoidant attachment will report that the time in between their partner's messages will be shorter than what they desire (H5b). We will also examine partner's actual and ideal message response intervals as separate outcomes.

6. When anxious (H6a) or avoidant (H6b) attachment is higher, the association Yes/No between message frequency satisfaction (MFS) and relationship quality will be stronger (more positive). In other words, anxiety or avoidance (or both) will moderate the effect of MFS in relation to relationship quality. 
Table 2. Sample Characteristics

\begin{tabular}{|c|c|c|}
\hline Variable & $n$ & $\%$ \\
\hline \multicolumn{3}{|l|}{ Gender identification } \\
\hline Man & 94 & 30.8 \\
\hline Woman & 210 & 68.9 \\
\hline Non-binary & 1 & 0.3 \\
\hline \multicolumn{3}{|l|}{ Partner gender identification } \\
\hline Man & 205 & 67.2 \\
\hline Woman & 98 & 32.1 \\
\hline Non-binary & 1 & 0.3 \\
\hline \multicolumn{3}{|l|}{ Sexual orientation } \\
\hline Exclusively heterosexual & 229 & 75.1 \\
\hline Mostly heterosexual & 38 & 12.5 \\
\hline Bisexual & 21 & 6.9 \\
\hline Mostly lesbian or gay & 5 & 1.6 \\
\hline Exclusively lesbian or gay & 5 & 1.6 \\
\hline Asexual & 3 & 1.0 \\
\hline Other (please describe) & 4 & 1.3 \\
\hline \multicolumn{3}{|l|}{ Relationship status characterization } \\
\hline Dating casually & 83 & 27.2 \\
\hline Serious relationship- not living together & 189 & 62.0 \\
\hline Serious relationship- living together & 23 & 7.5 \\
\hline Engaged- not living together & 2 & 0.7 \\
\hline Engaged- living together & 2 & 0.7 \\
\hline Married & 4 & 1.3 \\
\hline Other (please specify) & 2 & 0.7 \\
\hline \multicolumn{3}{|l|}{ Cohabitation status } \\
\hline Yes & 30 & 9.8 \\
\hline No & 274 & 89.8 \\
\hline \multicolumn{3}{|l|}{ Racial/ethnic identification } \\
\hline African/African American/Black & 13 & 4.3 \\
\hline Arab American/Middle Eastern & 4 & 1.3 \\
\hline Asian/Asian American & 30 & 9.8 \\
\hline Hispanic/Latina/o American & 54 & 17.7 \\
\hline Pacific Islander & 1 & 0.3 \\
\hline White/European American/Caucasian & 180 & 59.0 \\
\hline Biracial/Multiracial & 20 & 6.6 \\
\hline Other (please specify) & 3 & 1.0 \\
\hline
\end{tabular}


Table 3. Measures

\begin{tabular}{|c|c|c|c|c|c|}
\hline Variable or subscale & Measure or item & Low anchor & High anchor & $\alpha_{\text {prior }}$ & $\alpha_{\mathrm{obs}}$ \\
\hline Attachment & Experiences in Close Relationships Revised (ECR-R) ${ }^{13}$ & $\begin{array}{l}1 \text { (strongly } \\
\text { disagree) }\end{array}$ & $\begin{array}{l}7 \text { (strongly } \\
\text { agree) }\end{array}$ & - & - \\
\hline Anxiety & $\begin{array}{l}\text { "I often worry that my partner doesn't really love me." ( } 18 \\
\text { items) }\end{array}$ & - & - & $.95^{14}$ & .92 \\
\hline Avoidance & $\begin{array}{l}\text { "I prefer not to show a partner how I feel deep down." (18 } \\
\text { items) }\end{array}$ & - & - & $.93^{14}$ & .94 \\
\hline Relationship quality & $\begin{array}{l}\text { Relationship Assessment Scale (RAS) }{ }^{15} \\
\text { "In general, how satisfied are you with your relationship." (7 } \\
\text { items) }\end{array}$ & 1 (unsatisfied) & $\begin{array}{l}5 \text { (completely } \\
\text { satisfied) }\end{array}$ & $.86^{15}$ & .88 \\
\hline $\begin{array}{l}\text { Messaging frequency } \\
\text { satisfaction (MFS) }\end{array}$ & $\begin{array}{l}\text { "How satisfied are you with the frequency of your partner's } \\
\text { messages?" }\end{array}$ & $\begin{array}{l}1 \text { (completely } \\
\text { dissatisfied) }\end{array}$ & $\begin{array}{l}7 \text { (completely } \\
\text { satisfied) }\end{array}$ & - & - \\
\hline $\begin{array}{l}\text { Ideal messaging } \\
\text { frequency }\end{array}$ & $\begin{array}{l}\text { "Thinking about the frequency of messages from my } \\
\text { partner...I would like their messages to be..." }\end{array}$ & $\begin{array}{l}1 \text { (a lot less } \\
\text { frequent })\end{array}$ & $\begin{array}{l}7 \text { (a lot more } \\
\text { frequent) }\end{array}$ & - & - \\
\hline Messages sent & $\begin{array}{l}\text { "How many messages have you sent to your partner in the } \\
\text { last } 24 \text { hours?" }\end{array}$ & - & - & - & - \\
\hline Messages received & $\begin{array}{l}\text { "How many messages have you received from your partner } \\
\text { in the last } 24 \text { hours?" }\end{array}$ & - & - & - & - \\
\hline $\begin{array}{l}\text { Message response } \\
\text { latency: Self }\end{array}$ & $\begin{array}{l}\text { "How long does it typically take (in minutes) for you to } \\
\text { respond to your partner?" }\end{array}$ & - & - & - & - \\
\hline $\begin{array}{l}\text { Message response } \\
\text { latency: Partner }\end{array}$ & $\begin{array}{l}\text { "How long does it typically take (in minutes) for your } \\
\text { partner to respond to you?" }\end{array}$ & - & - & 一 & - \\
\hline Message interval: Typical & $\begin{array}{l}\text { "How many minutes typically pass between messages from } \\
\text { your current romantic partner?" }\end{array}$ & - & - & - & - \\
\hline Message interval: Ideal & $\begin{array}{l}\text { "Ideally, how many minutes would you like there to be } \\
\text { between messages from your current romantic partner?" }\end{array}$ & - & - & - & - \\
\hline
\end{tabular}

Note. $\alpha_{\text {prior }}=$ Cronbach's alpha from a prior publication. $\alpha_{\mathrm{obs}}=$ Cronbach's alpha observed in the present data. 
Table 4. Bivariate Correlations among and Descriptive Statistics for Variables

\begin{tabular}{|c|c|c|c|c|c|c|c|c|c|c|c|c|c|}
\hline Variable & 1 & 2 & 3 & 4 & 5 & 6 & 7 & 8 & 9 & 10 & 11 & 12 & 13 \\
\hline \multicolumn{14}{|l|}{ Attachment } \\
\hline \multicolumn{14}{|l|}{ 1. Anxious } \\
\hline 2. Avoidant & .38 & & & & & & & & & & & & \\
\hline \multicolumn{14}{|l|}{ Attitudes } \\
\hline 3. Relationship quality & -.48 & -.58 & & & & & & & & & & & \\
\hline 4. Message frequency satisfaction (MFS) & -.41 & -.21 & .45 & & & & & & & & & & \\
\hline 5. Ideal message frequency & .29 & -.05 & -.13 & -.32 & & & & & & & & & \\
\hline \multicolumn{14}{|l|}{ Behavior } \\
\hline 6. Messages sent ${ }^{a}$ & -.14 & -.18 & .14 & .25 & -.06 & & & & & & & & \\
\hline 7. Messages received ${ }^{a}$ & -.17 & -.14 & .15 & .32 & -.14 & .96 & & & & & & & \\
\hline 8. Message response latency: Self $^{a}$ & .06 & .22 & -.17 & -.15 & -.03 & -.11 & -.07 & & & & & & \\
\hline 9. Message response latency: Partner ${ }^{\mathrm{a}}$ & .23 & .13 & -.25 & -.39 & .33 & -.18 & -.24 & .63 & & & & & \\
\hline 10. Message response interval: Typical ${ }^{\mathrm{a}}$ & .13 & .02 & -.15 & -.39 & .22 & -.17 & -.21 & .52 & .71 & & & & \\
\hline 11. Message response Interval: Ideal ${ }^{\text {a }}$ & .01 & .15 & -.12 & -.20 & -.09 & -.16 & -.14 & .56 & .44 & .73 & & & \\
\hline \multicolumn{14}{|l|}{ Other variables } \\
\hline 12. Relationship duration (months) ${ }^{a}$ & -.21 & -.22 & .15 & .05 & -.05 & .05 & .03 & -.07 & .01 & .05 & -.01 & & \\
\hline 13. Gender $(-0.5=$ men, $0.5=$ women $)$ & .06 & -.07 & .05 & .04 & .12 & .13 & .10 & .03 & .10 & .11 & -.01 & .08 & \\
\hline \multicolumn{14}{|l|}{ Descriptive statistics } \\
\hline Mean & 3.21 & 2.64 & 4.13 & 5.71 & 4.46 & 3.60 & 3.59 & 1.98 & 2.17 & 2.40 & 2.08 & 2.35 & 0.19 \\
\hline$S D$ & 1.14 & 1.07 & 0.76 & 1.43 & 0.99 & 1.13 & 1.15 & 0.94 & 1.01 & 1.13 & 1.10 & 0.95 & 0.46 \\
\hline
\end{tabular}

Note. Ns $=293-302 .{ }^{\text {a }}$ Log-transformed variable (i.e., $\ln (x+1)$ ). Boldface: $p<.05$. 
Table 5. Attachment and Messages Sent and Received

\begin{tabular}{|c|c|c|c|c|c|c|}
\hline \multirow[b]{2}{*}{ Variable } & \multirow[b]{2}{*}{$b$} & \multirow[b]{2}{*}{$t$} & \multirow[b]{2}{*}{$p \leq$} & \multirow[b]{2}{*}{$r_{\mathrm{p}}$} & \multicolumn{2}{|c|}{$95 \% \mathrm{CI}$} \\
\hline & & & & & LL & $\mathrm{UL}$ \\
\hline \multicolumn{7}{|l|}{ Messages Sent ${ }^{\mathrm{a}}$} \\
\hline Anxious Attachment & -0.079 & -1.31 & .193 & -.08 & -.19 & .04 \\
\hline Avoidant Attachment & -0.160 & -2.48 & .014 & -.14 & -.25 & -.03 \\
\hline \multicolumn{7}{|l|}{ Messages Received ${ }^{\mathrm{a}}$} \\
\hline Anxious Attachment & -0.141 & -2.27 & .024 & -.13 & -.24 & -.02 \\
\hline Avoidant Attachment & -0.098 & -1.49 & .137 & -.09 & -.20 & .03 \\
\hline \multicolumn{7}{|c|}{ Messages Sent or Received ${ }^{a}$} \\
\hline Anxious Attachment & -0.105 & -1.68 & .095 & -.10 & -.21 & .02 \\
\hline Avoidant Attachment & -0.139 & -2.08 & .038 & -.12 & -.23 & -.01 \\
\hline
\end{tabular}

Note. $N \mathrm{~s}=301-302 .{ }^{a} \log$ numbers. $r_{\mathrm{p}}=$ partial correlation. $\mathrm{LL}=$ lower limit. $\mathrm{UL}=$ upper limit. 
Table 6. Attachment and Message Response Latency

\begin{tabular}{|c|c|c|c|c|c|c|}
\hline \multirow[b]{2}{*}{ Variable } & \multirow[b]{2}{*}{$b$} & \multirow[b]{2}{*}{$t$} & \multirow[b]{2}{*}{$p \leq$} & \multirow[b]{2}{*}{$r_{\mathrm{p}}$} & \multicolumn{2}{|c|}{$95 \% \mathrm{CI}$} \\
\hline & & & & & LL & $\mathrm{UL}$ \\
\hline \multicolumn{7}{|l|}{ Message Response Latency: Self ${ }^{a}$} \\
\hline Anxious Attachment & -0.027 & -0.53 & .597 & -.03 & -.14 & .08 \\
\hline Avoidant Attachment & 0.204 & 3.80 & .001 & .21 & .10 & .32 \\
\hline \multicolumn{7}{|l|}{ Messages Response Latency: Partner ${ }^{a}$} \\
\hline Anxious Attachment & 0.190 & 3.53 & .001 & .20 & .09 & .31 \\
\hline Avoidant Attachment & 0.049 & 0.86 & .390 & .05 & -.06 & .16 \\
\hline \multicolumn{7}{|l|}{ Message Response Latency: Self ${ }^{a}$} \\
\hline Messages Response Latency: Partner ${ }^{\mathrm{a}}$ & 0.595 & 14.24 & .001 & .64 & .56 & .70 \\
\hline Anxious Attachment & -0.140 & -3.52 & .001 & -.20 & -.31 & -.09 \\
\hline Avoidant Attachment & 0.174 & 4.21 & .001 & .24 & .13 & .34 \\
\hline
\end{tabular}

Note. $N=302 .{ }^{\text {a }}$ Log minutes. $r_{\mathrm{p}}=$ partial correlation. $\mathrm{LL}=$ lower limit. $\mathrm{UL}=$ upper limit. 
Table 7. Attachment and Message Response Intervals

\begin{tabular}{|c|c|c|c|c|c|c|}
\hline \multirow[b]{2}{*}{ Variable } & \multirow[b]{2}{*}{$b$} & \multirow[b]{2}{*}{$t$} & \multirow[b]{2}{*}{$p \leq$} & \multirow[b]{2}{*}{$r_{\mathrm{p}}$} & \multicolumn{2}{|c|}{$95 \% \mathrm{CI}$} \\
\hline & & & & & LL & UL \\
\hline \multicolumn{7}{|l|}{ Message Response Interval from Partner ${ }^{a}$} \\
\hline Anxious Attachment & 0.137 & 2.20 & .029 & .13 & .01 & .24 \\
\hline Avoidant Attachment & -0.032 & -0.49 & .627 & -.03 & -.14 & .09 \\
\hline \multicolumn{7}{|l|}{ Ideal Messages Response Interval from Partner ${ }^{a}$} \\
\hline Anxious Attachment & -0.051 & -0.85 & .396 & -.05 & -.16 & .07 \\
\hline Avoidant Attachment & 0.175 & 2.73 & .007 & .16 & .04 & .27 \\
\hline \multicolumn{7}{|l|}{ Message Response Interval from Partner ${ }^{a}$} \\
\hline Ideal Messages Response Interval from Partner ${ }^{a}$ & 0.793 & 19.39 & .001 & .75 & .70 & .80 \\
\hline Anxious Attachment & 0.171 & 4.16 & .001 & .24 & .13 & .34 \\
\hline Avoidant Attachment & -0.174 & -3.93 & .001 & -.23 & -.33 & -.11 \\
\hline
\end{tabular}

Note. $N \mathrm{~s}=291-294 .{ }^{\text {a }}$ Log minutes. $r_{\mathrm{p}}=$ partial correlation. $\mathrm{LL}=$ lower limit. UL $=$ upper limit. 
Table 8. Relationship Quality as Functions of Attachment and Message Frequency Satisfaction

\begin{tabular}{lcrrrrrr}
\hline & & & & & \multicolumn{2}{c}{$95 \%$ CI } \\
\cline { 6 - 8 } \multicolumn{1}{c}{ Variable } & \multicolumn{1}{c}{$b$} & $t(295)$ & $p \leq$ & $r_{\mathrm{p}}$ & LL & UL \\
\hline Anxious attachment & -0.132 & -4.04 & .001 & -.23 & -.33 & -.12 \\
Avoidant attachment & -0.329 & -10.21 & .001 & -.51 & -.59 & -.42 \\
Message Frequency Satisfaction (MFS) & 0.119 & 4.29 & .001 & .24 & .13 & .35 \\
Anxious $\times$ MFS & 0.045 & 1.99 & .048 & .11 & .00 & .23 \\
Avoidant $\times$ MFS & 0.012 & 0.50 & .617 & .03 & -.09 & .14 \\
Anxious $\times$ Avoidant & 0.045 & 1.59 & .112 & .09 & -.02 & .20 \\
\hline
\end{tabular}

Note. $N=302 . r_{\mathrm{p}}=$ partial correlation. $\mathrm{LL}=$ lower limit. $\mathrm{UL}=$ upper limit. 


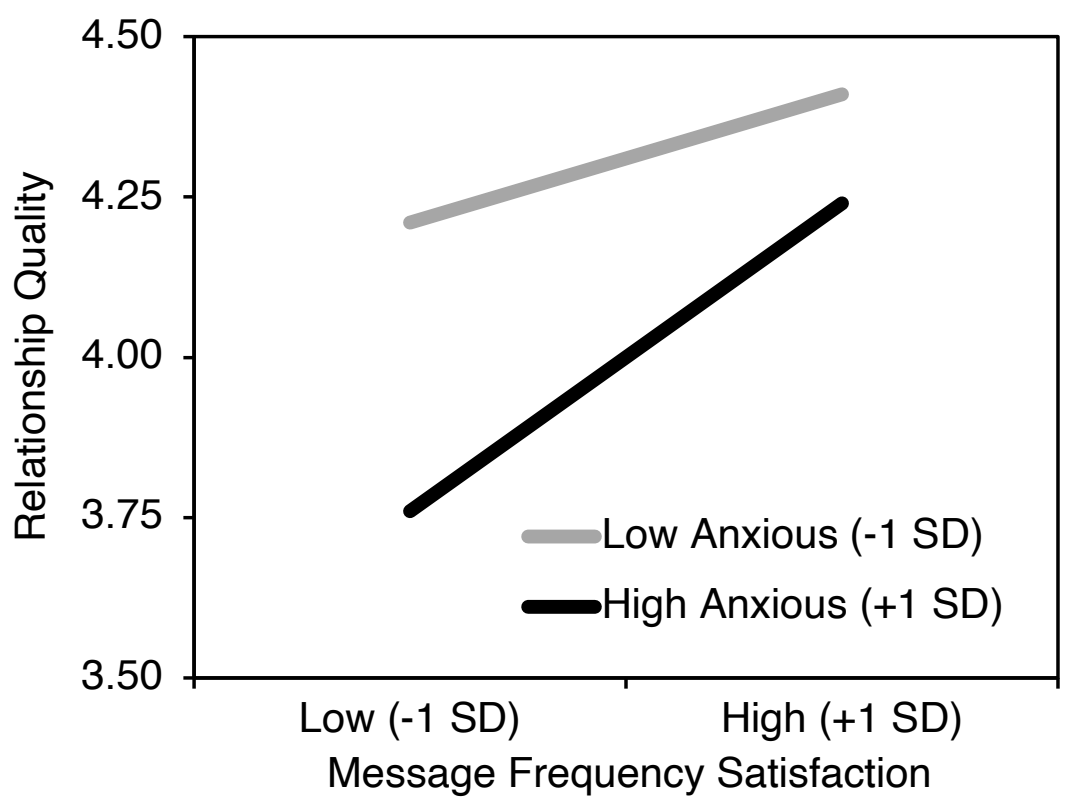

Figure 1. Relationship quality as functions of anxious attachment and message frequency satisfaction. 